\title{
El Nuevo diccionario francés-español y español-francés (1856) atribuido a Vicente Salvá
}

In: Bulletin Hispanique. Tome 108, º2, 2006. pp. 577-609.

\section{Resumen}

La composición del Nuevo diccionario fr.-esp. y esp.-fr. de 1856 se basó fundamentalmente en tres diccionarios: el de Capmany, el de Domínguez y el de Bescherelle. La influencia de estos dos últimos dificulta la asignación a Salva de la autoría de la obra. También la dificulta la propia historia del diccionario. Pero el prestigio del nombre de Salva, aprovechado por ciertos intereses comerciales, llevó a que la obra acabara atribuyéndose indebidamente a este insigne lexicógrafo.

\section{Abstract}

The Nuevo diccionario fr.-esp. y esp. fr. (1856) has been written from three main sources: Capmany 's dictionary, Domínguez 's and Bescherelle 's. Now, on one hand, the influence of the two last seems in opposition with the attribution of this work to Salva, and one the other hand, the actual story of the dictionary makes this attribution questionable too. However this attribution prevailed in the end as a resuit of the publishing house taking advantage ofthe prestige of Salva's mame.

\section{Résumé}

Le Nuevo diccionario fr.-esp. y esp.-fr. (1856) a été composé à partir de trois sources principales: le dictionnaire de Capmany, celui de Domínguez et celui de Bescherelle. Or, d'une part, l'influence de ces deux derniers semble s'opposer à l'attribution de l'ouvrage à Salva et, de l'autre, l'histoire même du dictionnaire rend également douteuse cette attribution. Celle-ci a pourtant fini par prévaloir comme résultat de la mise à profit du prestige du nom de Salva par la maison d'édition du dictionnaire.

Citer ce document / Cite this document :

Bruña Cuevas Manuel. El Nuevo diccionario francés-español y español-francés (1856) atribuido a Vicente Salvá. In: Bulletin Hispanique. Tome 108, №2, 2006. pp. 577-609.

doi : 10.3406/hispa.2006.5269

http://www.persee.fr/web/revues/home/prescript/article/hispa_0007-4640_2006_num_108_2_5269 


\title{
El Nuevo diccionario francés-español y español-francés (1856) atribuido a Vicente Salvá
}

\author{
Manuel Bruña Cuevas \\ Universidad de Sevilla
}

Le Nuevo diccionario fr.-esp. y esp.-fr. (1856) a été composé à partir de trois sources principales: le dictionnaire de Capmany, celui de Dominguez et celui de Bescherelle. Or, d'une part, l'influence de ces deux derniers semble s'opposer à l'attribution de l'ouvrage à Salvá et, de l'autre, l'histoire même du dictionnaire rend également douteuse cette attribution. Celle-ci a pourtant fini par prévaloir comme résultat de la mise à profit du prestige du nom de Salvá par la maison d'édition du dictionnaire.

La composición del Nuevo diccionario fr.-esp. y esp.-fr. de 1856 se basó fundamentalmente en tres diccionarios: el de Capmany, el de Dominguez y el de Bescherelle. La influencia de estos dos últimos dificulta la asignación a Salvá de la autoría de la obra. También la dificulta la propia historia del diccionario. Pero el prestigio del nombre de Salvá, aprovechado por ciertos intereses comerciales, llevó a que la obra acabara atribuyéndose indebidamente a este insigne lexicógrafo.

The Nuevo diccionario fr.-esp. y esp. fr. (1856) has been written from three main sources: Capmany's dictionary, Dominguez's and Bescherelle's. Now, on one hand, the influence of the two last seems in opposition with the attribution of this work to Salva, and one the other hand, the actual story of the dictionary makes this attribution questionable too. However this attribution prevailed in the end as a result of the publishing house taking advantage of the prestige of Salva's name.

Mots-clés : Vicente Salvá - J. B. Guim - F. de P. Noriega - Dictionnaire françaisespagnol - Diccionario francés-español - 1856.

$B H i$, Tome 108, n² 2 - décembre 2006 - p. 577 à 609. 


\section{BULLETIN HISPANIQUE}

$\mathrm{El}$ Nuevo diccionario francés-español y español-francés aparece en 1856, siete años después de la muerte de Salvá (1786-1849) ${ }^{1}$, a quien suele atribuírsele. En las dos portadas, correspondientes a las dos partes de la obra, se lee:

Nuevo diccionario francés-español [...] Arreglado con presencia de los materiales reunidos para esta obra por D. Vicente Salvá, y con otros sacados de los diccionarios antiguos y modernos mas acreditados; compuesto con mejor método, mas exacto, correcto y completo que todos los publicados hasta el dia, por D. J. B. Guim [...]

Nouveau dictionnaire espagnol-français [...] Rédigé d'après les matériaux réunis par $\mathrm{D}$. Vicente Salvá, et les meilleurs dictionnaires anciens et modernes, par F. de P. Noriega [...]

La redacción de estas portadas y el lugar preeminente que ocupa en ellas el nombre de Salvá parecen responder a una intención de presentar a este lexicógrafo como el verdadero autor de la obra. Ello nos lleva a preguntarnos cuál sería su verdadera participación en la elaboración de la misma. Pero, antes de responder a ello, comenzaremos por hacer un análisis del diccionario en sí.

\footnotetext{
1. La biografía de Salvá fue escrita por C. Reig Salvá (Vicente Salvá. Un valenciano de prestigio internacional, Valencia, Institución Alfonso el Magnánimo, Patronato José María Quadrado, CSIC, 1972). Puede encontrarse un resumen de su vida, basado en este libro, en la reedición de la Gramática de la lengua castellana de Salvá hecha por M. Lliteras (Madrid, Arco Libros, 1988, p. 13-24) y en La teoría gramatical de Vicente Salvá, Madrid, SGEL, 1992, p. 15-21, también de M. Lliteras. Véase también M. Mourelle Lema, "Datos inéditos para una biografía de Vicente Salvá", $B R A E, 45,1965$, p. 497-505. Por nuestra parte, haremos una observación en cuanto a la fecha del fallecimiento de Salvá. Reig Salvá (op. cit., p. 285) y Lliteras (op. cit., 1992, p. 20) sostienen que murió el 5 de mayo de 1849, a los cinco días de su llegada a París. Pero esto podría no ser exacto. P. Salvá y Mallén, hijo de Salvá, cuenta en su Catálogo de la biblioteca de Salvá (Valencia, Ferrer de Orga, 1872, p. VI) que su padre emprendió viaje a París, en el mes de mayo de 1849, "huyendo de los rigores caniculares" de España, y que en esta "capital murió el dia 5 de junio, cuatro después de su llegada». No hay, pues, coincidencia entre la fecha que da Reig Salvá y la de Salvá y Mallén. Pensamos que Reig Salvá seguramente se lió con los meses y los días. En efecto, por un lado, nos parece difícil que el hijo de don Vicente, tan unido a él, se equivocara de mes, y no acertamos a imaginar una razón que le llevara a falsear conscientemente la fecha. Por otro lado, su relato nos parece perfectamente coherente: Salvá deja España cuando empieza a apretar el calor (lo cual no suele ocurrir a principios, sino a tinales de mayo), llega a París al comenzar junio y fallece cuatro días después, o sea, el 5 de junio. Añadamos, por último, que tampoco puede tratarse de un lapsus ocasional el que Salvá y Mallén hable en el prólogo de junio y no de mayo, ya que en el interior del libro vuelve a referirse a junio: "Después de la muerte de mi padre acaecida en junio de 1849 nuestros sucesores de París, los Sres. Garnier hermanos, han publicado...» (Op. cit., p. 301).
} 


\section{LAS FUENTES}

El diccionario propiamente dicho va precedido de un «Prólogo», que, aunque supuestamente redactado por los responsables de la editorial Garnier, debió de serlo en realidad, dado su contenido, por los dos redactores de toda la obra, J. B. Guim y F. de P. Noriega.

\subsection{Los diccionarios criticados en el prólogo}

Este prólogo comienza haciendo una crítica de los diccionarios francésespañol más conocidos de entre los que se publicaron en la primera mitad del siglo XIX. Solo el más antiguo de ellos, el de Capmany, merece el respeto de los redactores. Todos los publicados posteriormente en París reciben, en cambio, comentarios desfavorables: el de Núñez de Taboada por ser una copia fiel del de Capmany y por los errores que sus pocas innovaciones encierran; el de Trapani y Rosily por haber pasado prácticamente inadvertido pese al bombo que quiso dársele; y los de Martínez López y Fonseca por no ser más que versiones resumidas del de Taboada ${ }^{2}$. En cuanto a los aparecidos en Madrid, el único criticado es el de Domínguez ${ }^{3}$.

2. A. de Capmany, Nuevo diccionario francés-español. En este van enmendados, corregidos, mejorados, y enriquecidos considerablemente los de Gattel, y Cormon, Madrid, Sancha, 1805; M. M. Núñez de Taboada, Dictionnaire français-espagnol et espagnol-français, plus complet et plus correct que tous ceux qui ont été publiés jusquà ce jour y compris celui de Capmany, París, BrunotLabbé, Rey et Gravier, T. Barrois, 1812; D. G. Trapani y A. de Rosily, Nouveau dictionnaire français-espagnol et espagnol-français avec la nouvelle orthographe de l'Académie espagnole rédigé d'après Gattel, Capmany, Taboada, Boiste, Laveaux etc., París, Thoisnier-Desplaces, 1826; P. Martínez López, Diccionario francés-español y español-francés conforme los mejores diccionarios franceses incluso el de la Academia, París, Charles Hingray, 1839; J. da Fonseca. Dictionnaire français-espagnol et espagnol-français avec la nouvelle orthographe de l'Académie espagnole; rédigé d'après Gattel, Sobrino, Nuñes de Taboada, Trapani, etc.; l'Académie française, Boiste, Laveaux, etc., París, Thiériot, 1840. Puede consultarse una bibliografía comentada de los estudios dedicados a estos y a otros diccionarios francés-español en M. Bruña Cuevas, "Los estudios sobre la lexicografía franco-española de todos los tiempos", Anales de Filologia Francesa (Universidad de Murcia), 11, 2003, p. 55-78.

3. R. J. Domínguez (1811-1848), Diccionario universal francés-español y español-francés, por una sociedad de profesores de ambas lenguas, bajo la dirección de D. Ramon Joaquin Dominguez, Madrid, Viuda de Jordán e Hijos (tomo I), Establecimiento léxico-tipográfico de R. J. Domínguez (tomos II a VI), 1845-1846. El prólogo del Nuevo diccionario de 1856 lo cree editado en 1848, pero no hubo tal edición. Tras la primera edición de 1845-1846, la segunda, que es seguramente con la que trabajaron Guim y Noriega, lleva fecha de 1853-1854 (Madrid, Mellado). 
Ahora bien, mientras que los comentarios sobre el conjunto de los diccionarios publicados en París solo ocupan un párrafo del prólogo, la crítica, directa o indirecta, del diccionario de Domínguez ocupa siete de las ocho páginas del mismo. Tanta atención a este último diccionario persigue convencer al lector de la mala calidad de la obra, a la que los redactores se refieren alguna vez como «el diccionario de Domínguez», pero de la que suelen hablar englobándola en un plural que intenta no darle demasiada publicidad: prefieren criticarlo bajo la apelación «les dictionnaires édités en Espagne». Por lo demás, y dejando aparte ciertas exageraciones puntuales, la crítica que el prólogo lanza contra el diccionario de Domínguez no está falta de fundamento; así, es verdad que éste presenta un carácter netamente enciclopédico, mal adaptado a la demanda del público mayoritario que compra diccionarios bilingües; y es cierto que fue compuesto con demasiado descuido, lo cual se manifiesta, por ejemplo, en una altísima cantidad de errores tipográficos, en una pronunciación figurada a menudo inexacta o en ciertas definiciones inapropiadas debido a que son una traducción equivocada o truncada del original francés que se tomó como modelo.

Tal original francés fue el Dictionnaire national de Bescherelle4, utilizado por el equipo que compuso la parte francés-español del diccionario de Domínguez ${ }^{5}$ como fuente para elaborar un diccionario bilingüe en el que, además de las equivalencias espańolas para las entradas francesas, se hallan, para la mayoría de éstas, verdaderas definiciones, similares o idénticas a las que podrían encontrarse en un diccionario monolingüe. Si la fuente del diccionario de Domínguez hubiera sido un diccionario como el de la Académie française, esas definiciones que acompañan en él a las equivalencias nunca hubieran sobrepasado unos límites razonables; pero, dado que su fuente es el Bescherelle, o sea, una obra de carácter enciclopédico, muchas de las definiciones del Domínguez mantuvieron ese mismo carácter, alcanzando así una amplitud desacostumbrada en la lexicografía bilingüe. Y si el Bescherelle ejerció esta influencia en la composición de las definiciones del Domínguez, también la ejerció en la selección de los lemas: el criterio seguido fue el de admitir desde el vocabulario más especializado hasta los términos

4. L.-N. Bescherelle (1802-1884), Dictionnaire national ou Dictionnaire universel de la langue française, París, Simon et Garnier, 1845-1846.

5. Parece ser que este diccionario, conforme a una de las tendencias que caracterizaron la lexicografía española del XIX, fue redactado por un equipo coordinado por Domínguez. Así se lee, al menos, en la portada (véase nuestra nota 3 ). 
más inusitados ${ }^{6}$. En cuanto a las equivalencias españolas para las entradas francesas, aunque a veces originales y bien halladas, en general están sacadas del diccionario de Capmany, ya sea directamente, ya -como nos parece lo más probable- por mediación del diccionario de Núñez de Taboada, plagio descarado del de Capmany ${ }^{7}$.

\subsection{Deseo de ocultar las fuentes}

Si hemos dedicado los párrafos anteriores a la descripción del diccionario de Domínguez es porque creemos que ello nos servirá para describir mejor el de Salvá. Por lo pronto nos permite comprender la facilidad que tuvieron Guim

6. El mismo carácter enciclopédico posee el Diccionario Nacional ó Gran Diccionario Clásico de la Lengua Española (Madrid, R. J. Domínguez, 1847-1848), cuyo autor es igualmente Domínguez y que también está inspirado, en gran parte, en el Dictionnaire national de Bescherelle. Sobre la lexicografía de carácter enciclopédico es un referente clásico A. Rey, Encyclopédies et dictionnaires, París, P.U.F., 1982. Véase también, sobre el mismo tema en la lexicografía hispánica, $H$. Hernández Hernández, «Del diccionario a la enciclopedia: los diccionarios enciclopédicos», Contribuciones al estudio de la lingüistica hispánica. Homenaje al profesor Ramón Trujillo, ed. por M. Almeida y J. Dorta, Barcelona, Montesinos, 1997, t. II, pp. 155-164, así como los varios trabajos dedicados al tema por I. Anaya Revuelta, entre los que solo recordaremos su libro La definición enciclopédica. Estudio del léxico ictionimico, Madrid, CSIC, 1999 y su artículo "Sobre el carácter enciclopédico de los diccionarios del español», Boletín de la RealAcademia Española, 80, cuaderno 279, 2000, p. 177-207. Para lo enciclopédico en el siglo XIX español, véanse D. Azorín Fernández, «La lexicografía española en el siglo XIX: del diccionario a la enciclopedia», Estudios de lingüistica. Universidad de Alicante (ELUA), 11, 1996-1997, p. 11 1-122 y J. Martínez Marín, «La lexicografía monolingüe del español en el siglo XIX: la corriente no académica", Cinco siglos de lexicografía del español, ed. por I. Ahumada, Jaén, Universidad de Jaén, 2000, p. 66-67 y 70-71. Sobre el enciclopedismo en la historia de los diccionarios francés-español, véase M. Bruña Cuevas, "Les dictionnaires encyclopédiques bilingues français-espagnol», Le Français face aux défis actuels. Histoire, Langue et culture, ed. por J. Suso López y R. López Carrillo, Granada, Universidad/APFUE/GILEC, 2004, tomo II, p. 35-44. Sobre la inclusión de tecnicismos en los diccionarios generales francés-español, véase, además de ese mismo trabajo de M. Bruña Cuevas, M. C. Cazorla Vivas, "El léxico técnico en los diccionarios bilingües español-francés de los siglos XVIII y XIX", Diccionarios y lenguas de especialidad, ed. por I. Ahumada Lara, Jaén, Universidad de Jaén, 2002, p. 120-130.

7. Taboada hasta se atrevió a incluir literalmente en la primera edición de su diccionario el polémico prólogo que Capmany había puesto al frente del suyo, lo que, en ediciones posteriores, obligó a la casa editora a defender la lengua francesa de los ataques que le había lanzado Capmany. Sobre esta cuestión puede consultarse M. Bruña Cuevas, «L'universalité de la langue française dans les grammaires de français pour les Espagnols et dans les dictionnaires bilingues antérieurs à 1815", Historiographia Linguistica, 26, 1/2, 1999, p. $54-57$ (reeditado en History of Linguistics in Spain II/ Historia de la Lingüistica en España II, ed. por E. F. K. Koerner y H.J. Niederehe, Amsterdam / Philadelphia, J. Benjamins, 2001, p. 229-262). 
y Noriega para criticar tan extensamente en su prólogo la obra de Domínguez. De la lectura de este prólogo parecería desprenderse que el diccionario de Domínguez, dadas las deficiencias que se le achacan, no se encuentra entre "los diccionarios antiguos y modernos mas acreditados", entre "les meilleurs dictionnaires anciens et modernes» a los que aluden como fuentes propias las dos portadas (la de la parte francés-español y la de la parte españolfrancés) del Nuevo diccionario atribuido a Salvá. Que así se piense nos parece ser, en efecto, el objetivo principal de una crítica tan extensa y despiadada. En su ímpetu demoledor, Guim y Noriega dicen incluso (p. II), con el fin de denostar más aun el diccionario de Domínguez, que los diccionarios de Taboada y de Capmany son, contrariamente a todos sus sucesores de París o Madrid, «buenos en el fondo», una afirmación que no extrañaría si hubiera sido aplicada solo al de Capmany, siempre bien considerado en el prólogo, pero que resulta sorprendente aplicada al de Taboada, fuertemente despreciado, como hemos visto, en los comentarios que se le dedican en la página precedente de ese mismo prólogo. He aquí el texto:

En el lugar que ocupan esas frases [las locuciones del diccionario de Domínguez] y su traduccion literal hubieran podido ponerse [...] las muchas cosas útiles que se hallan no solo en los Diccionarios franceses de donde se han copiado, sino en los de Capmany y Taboada, buenos en el fondo y que todos han debido tomar por base, habiéndolos copiado algunos demasiado servilmente. (Prólogo, p. II).

En realidad, si los ataques contra el Domínguez buscaban hacerle creer al lector que esta obra no se hallaba entre las fuentes modernas a las que aluden las portadas del Nuevo diccionario de 1856, los comentarios positivos sobre el Capmany procuran convencerlo de que este diccionario era una de sus fuentes antiguas; dado que la obra de Capmany no podía encontrarse ya en el mercado, hacerle buena publicidad no podía dañar los intereses comerciales de los editores del Nuevo diccionario. Tal no era el caso, en cambio, del Taboada, que seguía reeditándose cuando aparece el diccionario de 1856; pero Guim y Noriega sabían, y así lo expresan, que la parte francés-español de este diccionario era una copia literal del diccionario de Capmany ${ }^{8}$, lo que posiblemente les llevaría a afirmar que, como el de Capmany, era «bueno en el fondo»: solo «los artículos que añadió ó aumentó» Núñez de Taboada estaban llenos de errores, dice el prólogo del Nuevo diccionario (p. I). Así expresado, el comentario conjunto del prólogo sobre los diccionarios de Capmany y

8. Sólo la parte francés-español del Taboada era copia del Capmany por la simple razón de que este último no incluye una parte español-francés. 
Taboada era solamente una pequeńa concesión que permitía resaltar con mayor contundencia la mala calidad del diccionario de Domínguez.

Nótese en nuestra cita anterior la alusión a los diccionarios franceses de que había copiado Domínguez. Guim y Noriega hablan de ellos en plural, y de igual modo lo hacen, como hemos dicho, cuando, refiriéndose en realidad al diccionario de Domínguez, hablan de «los diccionarios editados en España». Pero sabían bien que el único diccionario monolingüe francés que había servido de base a los redactores del Domínguez era el de Bescherelle. Lo citan incluso explícitamente alguna vez como fuente del Domínguez. Lo que no hacen nunca es citarlo como fuente propia. Véase, por ejemplo, cómo se expresan, en lo relativo a sus propias fuentes, hacia el final del prólogo, después de varias páginas de críticas contra el Domínguez y antes de empezar a exponer las principales ventajas del Nuevo diccionario (como ya hemos dicho, los enunciadores del prólogo se supone que son los responsables de la editorial Garnier):

Dos literatos españoles muy laboriosos, á quienes hemos encargado este trabajo, ordenando y utilizando los materiales que dejó reunidos D. Vicente Salvá, lo han desempeñado concienzudamente y á satisfacción. Sin atenerse á los Diccionarios franceses-espańoles y españoles-franceses publicados en Madrid ó Paris, todos mas ó ménos defectuosos, como hemos advertido, y es fácil conocer, han tenido á la vista los mejores y mas modernos que se han escrito para los Franceses [...] (Prólogo, p. VII)

Obsérvese, en primer lugar, la contradicción flagrante entre lo dicho en esta cita y lo que se lee en la portada: en la portada se dice que el Nuevo diccionario fue redactado a partir de los materiales de Salvá y de «los diccionarios antiguos y modernos mas acreditados", mientras que en la cita que acabamos de hacer ya solo se habla de "los mejores y mas modernos. Y obsérvese asimismo que las únicas fuentes lexicográficas admitidas en esta cita son los mejores diccionarios monolingües franceses recientemente publicados, sin mención precisa, por lo demás, a ninguno de ellos; en la página I del prólogo se lee, en cambio, que la obra se compuso "con el auxilio de todos los Diccionarios últimamente impresos en España y Francia».

Contradicciones entre el prólogo y las portadas, contradicciones en el interior del prólogo, espacio desmesurado dedicado a la crítica del Domínguez, empleo del plural para hablar de un solo diccionario... Como se ve, las explicaciones del prólogo tienen toda la pinta de pretender borrar las pistas que pudieran llevar al descubrimiento de las fuentes lexicográficas del Nuevo diccionario. Solo se reconoce, y hasta se resalta, la aportación de los materiales legados por Salvá. 
¿Cuál es la verdad de todo esto? ¿Cuáles son realmente las fuentes lexicográficas de la obra? ¿Cuál es la verdadera aportación de Salvá a la composición del diccionario? Empezaremos por responder a las primeras de estas preguntas para ocuparnos luego de la contribución de Salvá.

\subsection{Rastreo de las fuentes}

El análisis de los artículos de la primera parte, francés-español, del Nuevo diccionario nos ha revelado que fue compuesto fundamentalmente a partir de tres diccionarios: los de Capmany / Taboada', Domínguez y Bescherelle.

Ahora bien, el diccionario de Domínguez, como ya hemos dicho, está redactado a partir de una adaptación de las definiciones que proporciona el Bescherelle y a partir de la incorporación de las equivalencias españolas para las entradas francesas proporcionadas por el Capmany / Taboada ${ }^{10}$. De ello se deduce que Guim, el redactor de la parte francés-español del Nuevo diccionario, repitió la misma operación ya llevada a cabo por el equipo de Domínguez. Solo que Guim contó con un nuevo aporte: el propio diccionario de Domínguez.

9. Si hablamos del diccionario de Capmany / Taboada es porque, como ya hemos dicho, el de Taboada es un plagio prácticamente literal del de Capmany. En el caso del diccionario de Domínguez, seguramente se partiría del Taboada y no del Capmany, ya que no homos encontrado ninguna referencia a éste en la obra, mientras que se cita el de Taboada en repetidas ocasiones (véanse las voces civade, cornier). Por otro lado, al no incluir el diccionario de Capmany una parte español-francés, como ya hemos dicho, el de Taboada, que sí la incluía, tuvo que ser guía para Domínguez. De hecho, también en esa parte español-francés del Domínguez (véanse aborrecedor o aboyar) se cita expresamente la obra de Núnez de Taboada (cf. M. C. Cazorla Vivas, «Lexicografía bilingüe del siglo XIX. La primera edición del Diccionario francés-españoly español-francés de R.-J. Domínguez", Adquisición, enseñanza y contraste de lenguas, bilingüismo y traducción, ed. por I. Doval Reixa y M. R. Pérez Rodríguez, Vigo, Universidad de Vigo, 2003, p. 68). En lo que respecta al Nuevo diccionario de 1856 , no tenemos datos para afirmar que los redactores consultaron uno u otro, el Capmany o el Taboada, por lo que, dada su similitud, preferimos hablar, al referirnos a sus fuentes, del diccionario de Capmany / Taboada.

10. La aportación original del diccionario de Domínguez consiste, pues, en la idea de hacer un diccionario bilingüe de carácter enciclopédico (en sentido amplio: largas definiciones y alto número de términos de especialidad entre las entradas) a partir del Bescherelle, así como en el enriquecimiento frecuente con nuevas correspondencias de las equivalencias espańolas dadas por el Taboada, en la traducción de las numerosas entradas sacadas del Bescherelle y no incluidas en el Taboada, y en la incorporación de la pronunciación figurada para tudas las entradas. Para un estudio general del diccionario bilingüe de Domínguez, véase M. C. Cazorla Vivas, op. cit., 2003 y M. Bruńa Cuevas, "Un diccionario bilingüe enciclopédico (Ramón Joaquín Domínguez, 1845-1846)", El texto como encrucijada. Estudios franceses y francófonos, ed. por M. J. Salinero Cascante e I. Ińarrea Las Heras, Logrońo, Universidad, 2003, tomo II, p. 283-294. 
En efecto en base a nuestro análisis del Nuevo diccionario hemos concluido que Guim tomó como guía básica el diccionario de Domínguez, aunque descargándolo de todo lo que le pareció inadecuado para un diccionario bilingüe por su carácter enciclopédico, redundante, anticuado o subjetivo ${ }^{11}$. Veamos un ejemplo de en qué consistió tal operación.

Domínguez. Gîte, s. m. ji-t. Yácija; albergue, dormitorio, vivienda donde se recoge á dormir una persona. = Posada nocturna, lugar donde se pernocta cuando se vá de viaje. || Cama; lecho donde se acuesta la liebre. || Prov. Un lièvre va toujours au gite; la liebre muere casi siempre cerca de donde tiene la cama; es decir que despues de haber corrido una persona muchos paises, siempre anhela morir en su patria. En un sentido análogo se dice tambien. Cet homme ressemble au lièvre, il vient mourir au gîte; este hombre parece á la liebre, que viene á morir donde tiene la querencia. = Il faut attendre le lièvre au gîte; cerca de la cama se encuentra la liebre, la querencia atrae al hombre. || Hist. Droit de gîte; derecho de hospedage, bajo este pretesto exigieron los reyes una retribucion equivalente á la que se hacían pagar, cuando en sus correrías pernoctaban en casa de algun grande ó señor feudal, || Gîte et geôlage; carcelaje, derecho que se pagaba antiguamente á los carceleros por la custodia y cuidado que dispensaban á los presos. En Espańa se abunda en este género de sacaliñas bajo innumerables pretextos, cuyas consecuencias, ademas de las de desidia, animosidad y ferocidad inhumana fuera de desear, que desapareciesen absolutamente hasta de las pájinas de la historia. II Artill. Gîtes; piezas de madera que sirven de base en la construccion de plataformas. \| Feud. Gîte aux chiens; derecho impuesto sobre los vasallos que rehusaban mantener los perros de caza del señor. I| Miner. Capa; masa de mineral relativamente á su posicion y á las substancias que contiene. || Art. Solera, piedra de molino que no tiene movimiento y sobre la que gira la muela. = Plano; parte inmóvil del fuelle.

Nuevo DiccionaRio. Gíte, m. git. Yáciga, albergue, vivienda donde se recoge á dormir una persona. || Posada, lugar donde se pernocta cuando se va de viaje. || Cama, lecho donde se acuesta la liebre. || prov. Un lièvre va toujours

11. Guim y Noriega aceptaron, en cambio, la idea de Domínguez de incorporar un sistema de pronunciación figurada para las entradas, si bien cambiaron los criterios para establecerla. Sobre la importancia tanto del Domínguez como del Nuevo diccionario de 1856 para la historia de la pronunciación figurada en la lexicografía francoespañola, véase $M$. Bruña Cuevas, "Histoire des transcriptions phonétiques dans les dictionnaires français-espagnol et espagnolfrançais", Cahiers de Lexicologie, 87, 2, 2005, p. 97-140. Para un estudio especialmente centrado en la historia de la transcripción de la pronunciación española, véase M. Bruña Cuevas, "La pronunciación figurada del español en los diccionarios bilingües español-francés (siglos XIXXX)», Hacia la unidad en la diversidad: difusión de las lenguas europeas, ed. por E. Fernández Vallina, V. González Martín y M. Montesinos Caperos, Salamanca, Diputación de Salamanca, 2002, p. 75-89. 
au gite, la liebre muere casi siempre cerca de donde tiene la cama; es decir, que despues de haber corrido una persona muchos países, siempre anhela morir en su patria. En un sentido análogo se dice tambien: cet homme ressemble au lièvre, il vient mourir au gîte, este hombre se parece á la liebre, que viene á morir donde tiene la querencia. || Il faut attendre le lièvre au gîte, cerca de la cama se encuentra la liebre, la querencia atrae al hombre. || Capa, masa de mineral relativamente á su posicion y á las sustancias que contiene. || Solera, piedra de molino que no tiene movimiento, y sobre la que gira la muela. \| Plano, parte inmóbil del fuelle. || Gîtes, pl. Arrill. Piezas de madera que sirven de base en la construccion de plataformas.

Obsérvese cómo, a pesar de la alta dosis de literalidad del artículo gîte redactado por Guim con respecto al de Domínguez, aquél ha suprimido las locuciones referentes a las costumbres feudales, así como el largo comentario subjetivo que incluye Domínguez cuando traspone esas realidades del pasado a la España de su época. Nótese igualmente cómo, en general, la puntuación y la ortografía de Guim son más cuidadas que las de Domínguez ${ }^{12}$.

Ahora bien, esta recomposición del Domínguez fue realizada por Guim teniendo constantemente a la vista los otros dos diccionarios que hemos señalado como fuentes suyas: el de Capmany / Taboada y el de Bescherelle. Guim recuperó algunas de las equivalencias, de las locuciones o de las acepciones que se encontraban en el Capmany / Taboada pero que no recogió Domínguez:

Domínguez. Glacer, v. a. gla-sé. Helar; congelar, endurecer, solidificar; quedar helada una cosa por la accion del frio. || Helar; congelar; someter un liquido á la accion del hielo combinado con la sal. || Helar; causar un frio excesivo, hablando del aire, de la lluvia, etc. || Fig. Helar; causar una emocion fuerte y desagradable hasta el punto de interceptar la circulacion de la sangre. = Helar; intimidar, dejar estupefacta á una persona con una repulsion brusca e inesperada. $=$ Helar; hacer perder el entusiasmo, la animacion, la resolucion que se tenía sobre algun asunto. || Poes. Helar; hacer perder el calor natural, el fuego que inspira la juventud ó la inesperiencia. || Conf. Bañar; cubrir con un baño brillante ó trasparente ciertos frutos, pastas ó confituras. \|Art. Guarnecer las viandas de una especie de jaletina ó substancia trasparente. $=$ Decocer la carne hasta que el caldo quede en estado de cuajarse. = Pint. Retocar; recargar los colores de un cuadro. || Art. Barnizar; dar lustre, pulimentar, bruñir; hacer que un mueble ó cosa semejante tome un brillo trasparente. = Frotar; sobrecoser, zurcir; hacer de modo que no se aperciban las costuras de un vestido. \| $\mathrm{Se}$-. pron. Helarse; ser helado en todas las acepciones del verbo activo.

12. Esta vez, no obstante, y contrariamente a lo que es frecuente, Guim no ha sabido corregir un error de Domínguez, concretamente el que este introdujo en la primera acepción escribiendo Yácija en vez de Yacija; la palabra, poco usada, sería desconocida para Guim, quien la corrigió erróneamente en Yáciga. 
NUEVO DICCIONARIO. GLACER, a. glasé. Helar, congelar las cosas líquidas. \| Congelar, someter un liquido á la accion del hielo combinado con la sal. \| Causar un frio excesivo, hablando del aire, de la lluvia, etc. \| met. Causar una emocion fuerte $y$ desagradable hasta el punto de interceptar la circulacion de la sangre. || Intimidar, dejar estupefacta á una persona con una repulsion inesperada. Son sérieux me glace, su gravedad me para, me corta, me deja atónito. || Hacer perder el entusiasmo, la animacion que se tenia sobre algun asunto. || Poét. Hacer perder el calor natural, el fuego que inspira la juventud ó la inexperiencia. || Bañar, cubrir con un baño brillante ó trasparente ciertos frutos, pastas ó confituras. \| Art. Guarnecer las viandas de una especie de jaletina ó sustancia trasparente. \| Cocer la carne hasta que el caldo quede en estado de cuajarse. || Pint. Retocar, recargar los colores de un cuadro. \| Barnizar; dar lustre, pulimentar. || Ribetear. Glacer une doublure de taffetas sur une étoffe, ribetear una tela con el forro de tafetan, echarle un vivo. \| Frotar, sobrecoser, zurcir, hacer de modo que no se perciban las costuras de un vestido. $\|$ Se glacer, r. Helarse, ser helado, en todas las acepciones del verbo activo.

Obsérvese cómo, en el caso de glacer, Guim mantiene prácticamente una literalidad completa con respecto a Domínguez, quien a su vez va siguiendo en su artículo el orden de las acepciones que presenta el Bescherelle. Los cambios introducidos por Guim se limitan a reducir un poco alguna de las acepciones y a no repetir la traducción por «helar» que Domínguez iba dando al principio para cada una de ellas. Pero, sobre todo, Guim introduce, en relación con el Domínguez, la traducción por «ribetear" para la acepción del campo semántico de la costura, acompañándola de un ejemplo. Pues bien, provienen del Capmany / Taboada tanto esta traducción con su ejemplo, como el que se ofrece previamente (Son sérieux me glace), como también la redacción de la primera de todas las acepciones:

Capmany. Glacer. $v$. a. Helar, congelar: las cosas líquidas = Helar: pasmar de frio los miembros = Giacer des confitures: bañar confites y otros dulces con azucar: y tambien garapinar = Glacer des viandes: rebozar, arrebozar = Glacer une doublure de taffetas sur une étoffe: ribetear una tela con el forro de tafetan, echarle un vivo = Son sérieux me glace: su gravedad me para, me encoge.

Y si es indudable que Guim trabajó teniendo a la vista los diccionarios de Domínguez y Capmany / Taboada, igual de evidente resulta que también tuvo delante el Bescherelle para corregir y completar el Domínguez. Así, incorporó algunas de las acepciones que se encontraban en este último diccionario pero que Domínguez no había incluido en el suyo. Véase el caso de habillage:

Domínguez. Habillage, s. m. a-bi-lla-j. Art. Preparacion; peladura, desuelle, escame, destripe; y toda operacion que se hace en la cocina antes de poner á hervir un ave, un pescado, la caza ó cualquier animal. || Habillage 
d'un veau; preparacion de una ternera; operacion que consiste en desollar, destripar y poner al animal en estado de entrar al fuego. En un sentido análogo se dice en términos de pescador, cazador, curtidor, alfavero, cartonero y otros hablando de toda preparacion preliminar del arte.

Nuevo diccionario. habillage, m. abillág. Coc. Preparacion, de las aves y demas animales de caza, ántes de asarlos. || Desmoche de una planta. \| Iluminacion de los naipes. || En un sentido análogo se dice en términos de pescador, cazador, curtidor, alfarero, cartonero y otros, hablando de toda preparacion preliminar del arte.

La primera acepción de Domínguez, así como lo relativo a habillage de veau, es un buen resumen, rico en equivalencias españolas, de lo que se lee en Bescherelle:

Bescherelle. habillage. s. m. (pr. $a-b i-i a-g e$ ). Art. culin. Apprêt que l'on fait subir à un animal pour le faire cuire. Si c'est un quadrupède, c'est le dépouiller de sa peau; si c'est un oiseau, c'est le plumer, l'évider, le piquer; si c'est un poisson, c'est le laver, le vider, le préparer à être cuit. L'habillage d'un lapin, d'une perdrix, d'une carpe. Faire l'habillage d'un brochet.

$\mathrm{C}$ Bouch. Habillage d'un veau, d'un mouton. Opération qui consiste à les écorcher, à les vider, à les mettre en état de pouvoir être apprêtés à la cuisine.

Guim, en cambio, ha preferido, para esta primera acepción, seguir el modelo que le ofrecía Capmany / Taboada:

Capmany. Habillage. s. m. (cocina.) Preparacion de las aves y carnes antes de asarlas, como el lardéo \&c.

El final de la definición de Domínguez sigue siendo un resumen del diccionario de Bescherelle. Este, del mismo modo que ha comenzado por dar un ejemplo referido al arte culinario, da luego otros referidos a muy diversas artes. Domínguez, en vez de copiarlos al pie de la letra, ha preferido enumerar las distintas artes en que es de uso el término habillage. Nótese que esta parte final de la definición del Domínguez la incluye literalmente Guim como final de la suya, no sin antes corregir, empero, la errata tipográfica de Domínguez (alfavero). Pero Guim, entre esta parte final sacada del Domínguez y la primera acepción sacada del Capmany / Taboada, introduce dos acepciones que no están ni en uno ni en otro; su fuente de inspiración es ahora claramente el Bescherelle, entre cuyos ejemplos se encuentran dos que corresponden a esas dos acepciones del Nuevo diccionario de 1856. Esto se lee en Bescherelle:

- Hortic. Habillage d'un arbre. Opération qui consiste à le couper à une certaine hauteur, et à en rafraîchir les racines avant de le planter. [...]

- Habillage des cartes à jouer. Enluminure des cartes. 
En otros casos, este control ejercido por Guim sobre el texto de Domínguez ayudándose del Bescherelle le permitió corregir ciertas traducciones erróneas que aquél había hecho de éste. Tal es el caso, como señala el prólogo, en la acepción habit d'arlequin de la entrada habit, donde es evidente que el equipo de Domínguez no entendió el término francés disparates que se hallaba en la definición de Bescherelle, confundiéndolo con el español disparates:

Bescherelle. habit. [...] - Fig. et fam. Habit d'arlequin. Un tout composé de parties disparates. Un ouvrage fait de morceaux pris chez différents auteurs.

Domínguez. Habit, [...] Fig. fam. Habit d'arlequin; cajon de sastre; obra de retazos; un todo compuesto de partes, disparates, una obra literaria cuyo autor ha recopilado la mayor y mas mala parte de varios autores.

NuEVo DICCIONARIO. habit, [...] met. y fam. Habit d'arlequin, cajon de sastre, obra de retazos, un todo compuesto de partes inconexas, centon literario.

Aunque más sutilmente, es evidente que la redacción de Guim también mejora, en el caso de pacage, la traducción del Bescherelle propuesta por Domínguez. Para traducir la observación de Bescherelle sobre que pacage «Se prend souvent pour Pâture», Domínguez escribe: «Algunas veces se entiende por pastura». Guim, en cambio, más preciso, escribe: «Algunas veces se toma por pâture, pastura ó pasto».

Guim se alejó también del subjetivismo exacerbado que impregna el diccionario de Domínguez ${ }^{13}$. Ya lo hemos comentado en el caso de gîte y puede también observarse en el de mantille. Nótese cómo Guim se limita

13. Sobre el subjetivismo en el diccionario bilingüe de Domínguez puede consultarse M. C. Cazorla Vivas, op. cit., 2003, p. 66-67 y M. Bruña Cuevas, "Un diccionario bilingüe...», op. cit., 2003, p. 289-292. Sobre el mismo rasgo en su diccionario monolingüe, véase $M$. Seco, "La definición lexicográfica subjetiva: el Diccionario de Domínguez", Estudios de lexicografia española, Madrid, Paraninfo, 1987, p. 165-177 y M. A. Esparza Torres, «Notas sobre el Diccionario Nacional de Ramón Joaquín Domínguez», Estudios de historiografia lingüistica hispánica ofrecidos a Hans Josef Niederehe, ed. por M. C. Henríquez Salido y M. A. Esparza Torres, Vigo, Universidade de Vigo, 1999, p. 54-57. Para un estudio del tema en ambos diccionarios de Domínguez, véase M. C. Cazorla Vivas, "La lexicografía como medio de expresión ideológica", Actas del $V$ Congreso Internacional de Historia de la Lengua Española, ed. por M. T. Echenique Elizondo y J. Sánchez Méndez, Madrid, Gredos, t. II, 2002, p. $1972-$ 1977. 
en este caso a copiar el primer enunciado de la definición de Domínguez, eliminando tanto los datos enciclopédicos como el comentario subjetivo subsecuente:

Domínguez. Mantille, s. f. man-ti-ll. : Mantilla; adorno y abrigo que usan las mujeres, que cae sobre la cabeza, hombros y espaldas; las hay de muchas especies, el color es por lo comun negro ó blanco, son mas ó menos ricas, mas ó menos bastas, y tambien las llaman mantellinas. Solamente las españolas saben llevarlas con aire y gracia, con garbo y gentileza, y les cae tan bien que hace inimitable su sal y donosura. Las francesas tambien se ponen mantillas, pero sentimos no poder decir que las llevan.

NUEVO DICCIONARIO. MANTILLE, f. mantill. Mantilla, adorno y abrigo que usan las mujeres.

También en el caso de jacobin y jacobinisme optó Domínguez por unas definiciones claramente enciclopédicas y subjetivistas:

Domínguez. Jacobin, [...] Polít. Jacobino; franciscano, terrorista, miembro ó individuo de la montaña, etc. con todos estos nombres eran conocidos los republicanos franceses adictos á las doctrinas y máximas furibundamente sangrientas de Robespierre, de Saint Just, de Fouquier Tinville y otros. Sus primeros clubs se reunian en las bóvedas de un exconvento de franciscanos; de ahí la denominacion. = Jacobino: partidario del jacobinismo; que profesa sus principios.

DOMíngUEZ. Jacobinisme, [...] Pol. Jacobinismo; sistema de los jacobinos, que es una democrácia hiperbólica basada sobre principios ad hoc, esto es, ad terrorem. Los furiosos secuaces de tan bárbaro gobierno, que ha manchado la historia con páginas de sangre inocente deberian ser conducidos á una casa de locos, y amarrados á un poste con poderosas cadenas, para vindicacion de la misma humanidad que aparentan defender, no saciándose de degollarla.

Y de nuevo vemos cómo Guim elimina todo rasgo subjetivo en los artículos correspondientes de su diccionario y cómo suprime también lo enciclopédico ${ }^{14}$ :

14. Podría tenerse la impresión de que Guim adopta definiciones en círculo, puesto que define jacobin en relación con jacobinisme y viceversa. Pero ese juicio, que sería válido si de un diccionario monolingüe se tratara, no es de recibo tratándose de un diccionario bilingüe, el cual, en principio, no tiene por qué definir los términos cuyos equivalentes ofrece en otra lengua. Por lo demás, la supresión de lo subjetivo que Guim lleva a cabo en éste como en otros casos no debe inducir a pensar que el Nuevo diccionario de 1856 excluye sistemáticamente lo subjetivo y lo enciclopédico en todos sus artículos. Mal podía ser así tratándose de un diccionario tan influido por Domínguez y Bescherelle. Pero sí es cierto que salta a la vista el esfuerzo de Guim por atemperar esos rasgos característicos de sus fuentes. 
NUEVo dicCIONARIO. JaCobin, [...] Jacobino, partidario del jacobinismo.

NUEVO DICCIONARIO. JaCobinisme, [...] Jacobinismo, sistema, doctrina de los revolucionarios llamados jacobinos.

El resultado de todos estos cambios, de todas las operaciones de adaptación de sus fuentes realizadas por Guim, fue un diccionario mejor presentado, más corto, de manejo más cómodo, mejor adaptado a la demanda del público mayoritario interesado por los diccionarios francés-español: un buen diccionario, en suma.

Pero, por bueno que sea el Nuevo diccionario, su prólogo miente. Dice, como hemos visto en una de nuestras citas, que la obra estaba basada únicamente en los diccionarios monolingües franceses más recientes, lo cual, además de ser falso, denota falta de honradez, al no confesar que la fuente lexicográfica monolingüe realmente usada como guía había sido el Bescherelle. Y miente, sobre todo, porque oculta que el diccionario bilingüe que más denigra, es decir, el de Domínguez, había sido el punto de partida para la confección de la nueva obra. Y si esto es cierto para la parte francés-español, no deja de serlo para la parte español-francés, donde el Bescherelle no era de gran ayuda ${ }^{15}$.

Reconocer abiertamente las fuentes de las que se partía, al modo como lo habían hecho hasta entonces la mayoría de los diccionarios francés-español ${ }^{16}$, habría sido un rasgo de honradez y un signo de seguridad en cuanto a la valía de la nueva obra quc sc lanzaba al mercado. En el hecho de que se ocultaran solo podemos ver, en cambio, una falta de probidad intelectual y comercial para la que únicamente se nos ocurren dos explicaciones. La primera sería que los redactores del Nuevo diccionario tuvieran un sentimiento -solo en parte justificado- de haber plagiado la obra ajena después de haberla desprestigiado. La segunda, que la editorial Garnier se desquitara así de la misma falta de

15. La parte español-francés, a pesar de que recoge con frecuencia voces exóticas de las incluidas por Domínguez en su diccionario, no incorpora, en cambio, las voces antiguas que Salvá añadió a su diccionario del español y que no se hallaban por entonces en el de la Real Academia (véase nuestra nota 29). Es sorprendente que Noriega siguiera más fielmente la obra de Domínguez que la propia obra del autor cuyos materiales, según la portada, había utilizado.

16. Véase nuestra nota 2; podrá comprobarse que todos los diccionarios citados en ella declaran en portada las fuentes de que se inspiraron. Otra cosa es la veracidad de tales declaraciones, cuestión en la que no podemos detenernos ahora, si bien puede consultarse, en lo relativo al diccionario de Capmany, M. Bruña Cuevas, «Las mejoras aportadas a la traducción por el diccionario de Capmany (1805)», La traducción en España (1750-1830). Lengua, literatura, cultura, ed. por F. Lafarga, Lérida, Edicions de la Universitat de Lleida, 1999, p. 99-110. 


\section{BULLETIN HISPANIQUE}

honradez de que hizo gala Domínguez. Este, tanto en su diccionario bilingüe como en su diccionario monolingüe castellano, realiza una operación de trasvase de los contenidos que encontró en el Bescherelle, sin por ello mencionarlo ni en las portadas ni en los prólogos; pues bien, el Bescherelle lo editaba la casa Garnier, que quizá decidiera pagarle a Domínguez con la misma moneda ${ }^{17}$.

\section{El LEGADO DE SALVÁ}

¿Y los materiales legados por Salvá? ¿Realmente existieron? Vistas las inexactitudes o mentiras que ha sacado a la luz nuestro análisis del Nuevo diccionario y su prólogo, nos parece necesario preguntarnos si la editorial y los redactores de la obra no habrán faltado a la verdad también sobre ello.

\subsection{El proyecto de diccionario francés-español de Salvá}

No dudamos de que Salvá comenzara a componer un diccionario bilingüe francés-español. Es una idea que tenía en mente al menos desde que abrió su Librería Hispano-Americana en París. Acababa de abrirla cuando le dice por carta a su hijo que desea una librería

en que se den a los precios más baratos que se pueda los libros de España y donde haya el fondo de ediciones que yo me propongo hacer. Desde luego voy a estereotipar el Diccionario latino-español de Valbuena en un volumen como el más delgado del de Nuñez de Taboada [...] (París, 22-6-1830; según Reig Salvá, op. cit., p. 127).

Como se ve, para el fondo de librería que Salvá quería forjarse pensaba ya en un diccionario de Núnez de Taboada. Las indicaciones que da esta carta no bastan para saber si se refería al diccionario francés-español de Taboada (1812)

17. El posible desquite estaría tanto másjustificadocuantoque Domínguezera también editor. Editó en su propia imprenta, el "Establecimiento Léxico-tipográfico de R. J. Domínguez», los dos tomos de su Diccionario Nacional ó Gran Diccionario Clásico de la Lengua Española y cinco de los seis tomos de su Diccionario universal Francés-Españoly Español-Francés. Ciertamente, en 1856 el editor de estos dos diccionarios ya no era Domínguez, muerto en defensa de sus ideas durante la asonada madrileña de 1848; pero el nuevo editor, Mellado, no había cambiado -ni cabía esperar que lo hiciera- las portadas y los prólogos originales en lo que se refiere al tema que estamos tratando. Sobre la vida y circunstancias de la muerte de Domínguez, consúltese M. Seco, "Ramón Joaquín Domínguez», Estudios de lexicografía española, Madrid, Paraninfo, 1987, p. 152-164. 
o a su Diccionario de la lengua castellana (París, Seguin, 1825). Dos hechos, sin embargo, nos hacen sospechar que se trataba del bilingüe. Por un lado, en 1838 la librería de Salvá da a la luz un diccionario monolingüe del español; pero se trata de una edición revisada del Diccionario de la Real Academia: Diccionario de la lengua castellana, por la Academia española, reimpreso de la octava edición publicada en Madrid en 1837, con algunas mejoras, por D. Vicente Salvá. Nos extrañaría, pues, que en ningún momento de su vida Salvá hubiera pensado en revisar el diccionario monolingüe español de Taboada, máxime cuando éste no era, a su vez, sino una versión del de la Academia Española. La segunda razón que nos hace pensar que Salvá se refería en su carta de 1830 al diccionario bilingüe de Taboada es que Reig Salvá ${ }^{18}$ dice haber tenido ante los ojos un catálogo de la librería de Salvá, con fecha de uno de julio de 1832, donde se podía leer (páginas 8 y 13) que nuestro autor andaba atareado por entonces en la elaboración de un Diccionario francés-españoly de un Diccionario español-francés, cuyo plan de redacción ya expone; a la luz de este dato, cabe interpretar que en la carta de 1830 Salvá anunciaba ya a su hijo la intención de publicar un diccionario francés-español y que ese proyecto seguía en pie cuando aparece el catálogo de su librería del año 1832.

Ahora bien, lo igualmente seguro es que no pudo lograr por esa época dar cumplimiento a tal proyecto. Entre 1830 y 1832 no había podido dedicarse a él porque había estado ocupado en dos grandes empresas: su Gramática de la lengua castellana según ahora se habla ${ }^{19}$ y la primcra dc sus ediciones del Diccionario latino-español de Valbuena ${ }^{20}$. Posteriormente también le faltaría

18. Op. cit., p. 309.

19. París, Librería Hispano-Americana. La portada lleva fecha de 1830 , pero apareció realmente en 1831; Salvá lo hizo así, según Reig Salvá (op. cit., p. 141-142), para poder afirmar que Alcalá Galiano, que leyó el manuscrito, era profesor de la Universidad de Londres y para disimular que no se lo había querido enseñar a algunos españoles residentes en París en 1831, particularmente a Martínez de la Rosa. Durante buena parte de 1830, en efecto, Salvá se hallaba aún en Londres: se exilió a Gibraltar en 1823, a finales de 1824 se instaló con su familia en la capital inglesa, donde abrió su Librería Española y Clásica, y se trasladó de Londres a París en el transcurso de 1830. Para entender la importancia de la gramática de Salvá son fundamentales las obras de Lliteras (op. cit., 1988, 1992); entre los estudios posteriores, véanse M. J. Martínez Alcaide, "Vicente Salvá», Corpus représentatif des grammaires et des traditions linguistiques, t. 1, 1998, p. 311-313; M. C. Henríquez Salido, «La formación de palabras en la Gramática de la lengua castellana según ahora se habla de Vicente Salvám, Estudios de Historiografia Lingüistica. Actas del III Congreso Internacional de la Sociedad Española de Historiografia Lingüistica, ed. por M. A. Esparza Torres, B. Fernández Salgado y H.J. Niederehe, Hamburgo, Helmut Buske, 2002; M. A. K. Unger, "Aspectos ideológicos en la Gramática de Vicente Salvá", Res diachronicae, 2, 2003.

20. París, Salvá, 1832. 
tiempo para acometer en serio la composición del anunciado diccionario francoespañol ${ }^{21}$. Uno de los importantes proyectos que más tarde llevó a cabo fue, como ya hemos señalado, la publicación de una versión mejorada de la octava edición del Diccionario de la Real Academia; pese a otras publicaciones de menor calado, pese a su regreso a España (1834) tras la amnistía concedida a los liberales exiliados, pese a su reelección como diputado en Cortes por Valencia, este diccionario aparece finalmente, en París, en 1838. Pero, para lograrlo, Salvá tuvo que aplazar una ver. más su proyecto de diccionario bilingüe francés-español.

Esta imposibilidad de sacarlo adelante se entiende mejor si se considera que, seguramente, no se trataría para él tan solo de copiar un diccionario bilingüe ya existente y de publicarlo a su nombre, como hicieron otros. No es eso, por lo menos, lo que realizó en el caso de su edición del Diccionario de la Real Academia: aunque lo editara en 1838 como tal diccionario de la Academia "con algunas mejoras", su aportación había sido considerable; y lo será aún más en la reedición de 1841 y, sobre todo, en la de 1843, compuesta ya a partir de la novena edición del Diccionario de la institución académica. Sus ańadidos y mejoras a esta última fueron tan importantes que la obra resultante puede considerarse como propia ${ }^{22}$, lo que explica que, en 1846, se decidiera a publicarla por fin a su nombre con el título de Nuevo diccionario de la lengua castellana ${ }^{23}$. Está claro que si, partiendo del diccionario de Taboada

21. Era este el tercer diccionario bilingüe en el que Salvá había de trabajar. Además de su versión del latino-español de Valbuena, también colaboró en el Diccionario de las lenguas española e inglesa de Newman y Baretti que M. Seoane publicó en 1831 (Londres, V. Clowes). Según C. Reig Salvá (op. cit., p. 31-34), Salvá revisó toda la parte inglés-español de esta obra, así como unas doscientas páginas de la parte español-inglés. El propio Seoane reconoce en el prólogo que le debe muchas mejoras. Según P. Salvá y Mallén (op. cit., n²350), Salvá ayudó a Seoane incluso en la corrección de las pruebas.

22. Véase D. Azorín Fernández, «La labor lexicográfica de Vicente Salvá: su Nuevo diccionario de la lengua castellana", Los diccionarios del español en su perspectiva bistórica, Alicante, Publicaciones de la Universidad de Alicante, 2000, 258-259.

23. París, V. Salvá, 1846. La crítica actual está de acuerdo en considerar a Salvá como uno de los mayores -si no el mayor- lexicógrafos peninsulares del siglo XIX. Así lo expresa M. Seco, por ejemplo: «Vicente Salvá es el lexicógrafo mejor preparado de ese momento [1842-1853] y sin duda también de todo el siglo XIX.» («El nacimiento de la lexicografía moderna no académica», Estudios de lexicografía española, Madrid, Paraninfo, 1987, p. 151). Para su obra lexicográfica monolingüe remitimos al ya clásico trabajo de $\mathrm{M}$. Seco que acabamos de citar (especialmente p. 143-145 y 147-149) y a los estudios que le ha venido dedicando D. Azorín Fernández desde hace años; entre los más antiguos de esta investigadora, realizados en colaboración con R. Baquero Mesa, están «Los americanismos en el Nuevo Diccionario de la Lengua Castellana de Vicente Salvá", Actas del II Congreso Internacional de Historia de la Lengua Española, Sevilla, Pabellón de España, 1992, p. 963-970 y «De la teoría a la práctica 
o del de Capmany ${ }^{24}$, quería hacer en lo relativo a su diccionario bilingüe francés-español lo mismo que hizo para su diccionario monolingüe, el tiempo para componerlo tenía que faltarle por fuerza.

Y, sin embargo, Salvá no cejó en su empeño. Siempre según Reig Salvá, «en marzo de 1840 publicó un largo prospecto de su Diccionario francés-español con una muestra de ambas partes ${ }^{25}$. No hemos podido consultarlo, pero de ello habría que deducir que, en 1840 , el plan de la obra estaba ya plenamente definido y que la redacción de algunos de sus artículos estaba completamente terminada. Es un hecho que parece confirmar el testamento de Salvá, fechado el 30 de junio de $1840^{26}$, donde se especifica el valor pecuniario de los clichés correspondientes a las varias obras editadas por su librería: entre tales clichés se encontraban los de un Diccionario francés-español. Cuesta creer que estos clichés a los que alude el testamento sean los que sirvieron para imprimir el prospecto de 1840 , ya que no hubieran tenido tanto valor como para

lexicográfica: El Nuevo diccionario de la lengua castellana de Vicente Salvám, Estudios de Lingüistica. Universidad de Alicante (ELUA), 10, 1994-1995, p. 9-20; entre los más recientes, firmados sólo por Azorín Fernández, véanse, además del ya citado de 2000, los siguientes: «El léxico de especialidad en el Nuevo Diccionario de la Lengua Castellana (1846) de Vicente Salvá», Presente y futuro de la Lingüistica en España, ed. por A. Bernabé, J. A. Berenguer, M. Cantarero y J. C. de Torres, Madrid, Sociedad Española de Lingüística, 2002, p. 329-337; “Un proyecto original en la lexicografía española del siglo XIX: el Nuevo diccionario de la lengua castellana (1846) de Vicente Salvám, Lexicografía y Lexicologia en Europa y América. Homenaje a Gïnther Haensch en su 80 aniversario, coord. por M. T. Echenique Elizondo y J. Sánchez Méndez, Madrid, Gredos, 2003, p. 115-131. También P. Álvarez de Miranda ha publicado últimamente interesantes estudios sobre el diccionario monolingüe de Salvá, tanto en su versión definitiva de 1846 como en sus versiones previas de 1838 y 1841: «En torno al Nuevo diccionario de la lengua castellana (1846-1847) de Vicente Salvá», Actas del V Congreso Internacional de Historia de la Lengua Española, ed. por M. T. Echenique Elizondo y J. Sánchez Méndez, Madrid, Gredos, 2002, t. II, p. 1875-1886; “Vicente Salvá, editor y corrector del Diccionario de la Academia (1838 y 1841)", Lexicografia y Lexicología en Europa y América... (op. cit.), p. 99-114.

24. Aunque Salvá, en la carta de 1830 que hemos citado, habla sólo de Núñez de Taboada, era también buen conocedor de la obra de Capmany (1742-1813), cuyo Arte de traducir (Madrid, A. de Sancha, 1776) reeditó en colaboración con Alcalá Galiano: Arte de traducir el idioma francés al castellano compuesto por D. Antonio de Capmany; revisto y aumentado ahora por D. Antonio Alcalá Galiano y por el editor D. Vicente Salvá, París, V. Salvá, 1835. Para un estudio del prólogo que los dos editores pusieron a esta reedición, consúltese F. Lafarga, «Alcalá Galiano y V. Salvá ante la traducción. A propósito de una nueva edición del Arte de traducir de A. de Capmany (1835)", Neoclásicos y románticos ante la traducción, ed. por F. Lafarga, C. Palacios y A. Saura, Murcia, Scrvicio de Publicacioncs de la Univcrsidad, 2002, p. 155 164. El Arte de traducir será fuente de inspiración para Salvá en su Gramática para los españoles (véase nota 28).

25. C. Reig Salvá, op. cit., p. 311.

26. C. Reig Salvá, op. cit., p. 286-303. 
consignarlos en un documento tan importante; más bien nos inclinamos a pensar que corresponden a los estereotipos de que habla su hijo en el catálogo de su biblioteca de libros raros, asunto del que nos ocuparemos más adelante.

Con una parte de los clichés del diccionario ya hechos e incluso con una muestra del mismo ya publicada, ¿qué es lo que pudo impedir la aparición del diccionario bilingüe francés-español proyectado por Salvá desde 1830?

En 1841 nuestro autor tuvo que aminorar su actividad intelectual: andaba aquejado de fuertes dolores de cabeza ${ }^{27}$. A la espera de que se le pasaran, emprendió una gira por diversas ciudades españolas para comprar libros antiguos; era un viaje que, siendo productivo, podía además favorecer un restablecimiento más rápido de su estado de salud. Su hijo, no obstante, temía seguramente que Salvá siguiera empecinado en adelantar su proyectado diccionario francés-espańol. A una de sus cartas, en que aludía a este asunto, Salvá le respondía de esta guisa:

No temas que por más que Mr. Bourgoing u otro pongan [al] corriente la parte española-francesa del Diccionario, emprenda yo la mía, hasta que mi cabeza esté para ello; pero si algo he de hacer en esta vida, solo o auxiliado de otro, es esa obra; por estar ya más que principiada y porque nos sería de una gran utilidad. (Madrid, 31-8-1841; citado por C. Reig Salvá, op. cit., p. 242).

Esta carta contiene varios datos de interés. Por un lado, descubre la importancia económica que Salvá atribuía al diccionario bilingüe en ciernes. Su librería, en efecto, editaba regularmente su propia gramática castellana, su versión del diccionario de la Real Academia y el bilingüe latín-español de Valbuena; en la serie faltaba claramente un diccionario francés-español. El testamento de Salvá nos informa, como hemos dicho, sobre el alto valor pecuniario de los clichés ya preparados para esta última obra.

Por otro lado, el texto que acabamos de citar menciona a un tal Bourgoing, encargado de poner al día la parte español-francés de la obra en preparación; parece deducirse de ello que Salvá solamente se ocupaba, al menos por aquella época, de la otra parte del diccionario, la parte francés-español, interpretación que viene a confirmar la expresión «solo o auxiliado de otro».

27. El propio Salvá se refiere a estos dolores en el prólogo que redactó para la segunda edición (1841) de su Diccionario de la lengua castellana: «Tales son las mejoras [...] Aquellas les probarán que si el estado débil de mi cabeza no me permite continuar al presente las empresas que requieren más atención asidua y seria, no renuncio por ello al esmero [...]" (citado por P. Álvarez de Miranda, op. cit., 2003, p. 112). 
La cita anterior, por último, nos revela la firme decisión de Salvá de no dejar sin terminar una obra en la que venía pensando desde hacía tanto tiempo. Lo que esa cita no nos descubre, en cambio, es la extensión o la importancia de la parte ya elaborada de la obra; leemos que se encontraba ya "mas que principiada», pero esta expresión se presta a múltiples interpretaciones: ¿una treintena de sus primeros artículos, casi toda la letra $\mathrm{A}$, un tercio de la obra...?

Pese a la resuelta voluntad de llevar a buen puerto la publicación de un diccionario francés-español, éste no tiene visos de haber rebasado, en vida de Salvá, el estadio en que se hallaba cuando redactó su testamento de 1840. Entre las correcciones posteriores de tal testamento no parece que haya ninguna referida a los clichés ya listos en esa fecha. Suponemos, por ende, que es, o bien a estos clichés, o bien, más probablemente, al prospecto publicado en 1840, a lo que aluden, en 1856, los redactores del prólogo del Nuevo diccionario cuando afirman esto: "Nuestro predecesor D. Vicente Salvá empezó en 1840 la publicación de su Diccionario frances-español y español-frances.» (Prólogo, p. I). Sabemos que Salvá tuvo que restar brío durante un año a su ritmo de trabajo por mor de sus dolores de cabeza, pero después lo vemos de nuevo plenamente embebido en sus publicaciones y negocios editoriales; fue precisamente con motivo de un viaje a París para ocuparse de su librería cuando se topó con la muerte (1849), víctima de una de las epidemias de cólera que azotaron esta ciudad en el siglo XIX. Y, sin embargo, pese a su actividad recuperada, su diccionario bilingüe no progresó. Podría pensarse que son justamente esas otras ocupaciones las que siguieron impidiéndole dedicarse a él ${ }^{28}$, pero también podría pensarse que se lo estorbó un factor inesperado: la publicación en 1845-1846 del diccionario bilingüe de Domínguez.

Ya hemos explicado que este diccionario responde a un modelo nuevo. Si Salvá había partido para hacer el suyo del modelo usual en su época, el de Capmany / Taboada, su propia inquietud intelectual le llevaría, al examinar el diccionario de Domínguez, a considerar como insatisfactorios sus clichés de 1840. Un impresor que no hubiera sido al mismo tiempo un gran lexicógrafo no hubiera dudado, probablemente, en utilizar los clichés ya preparados; pero uno se imagina difícilmente a Salvá publicando un diccionario de corte

28. Entre las publicaciones que lanzó por entonces se halla una especialmente significativa para nosotros. En 1847 publica su Gramática para los españoles que deseen aprender la lengua francesa sin olvidar la propiedad y el giro de la suya, París, Salvá. Ya se ve que, si Salvá dejó paralizado durante este periodo su diccionario bilingüe, por lo menos no abandonó el campo de los estudios contrastivos francés-español. 
tradicional como si el de Domínguez no hubiera aparecido. Es muy posible que Salvá no hubiera estado de acuerdo con Domínguez en lo que atañe a la incorporación a un diccionario bilingüe de tantos términos de especialidad ${ }^{29}$, que hubiera evitado o reducido sus definiciones enciclopédicas, que le hubiera resultado sencillo corregir las muchísimas imperfecciones técnicas, gramaticales y demás del diccionario de Domínguez; es seguro, ya que tuvo oportunidad de expresarse sobre ello ${ }^{30}$, que hubiera rehuido el subjetivismo extremo que caracteriza la obra de Domínguez. Pero solo el número de acepciones nuevas sacadas del Bescherelle e incorporadas por Domínguez a su obra para la mayoría de las entradas era tal en relación con los diccionarios de Capmany o Taboada que Salvá se percataría de que no podía publicar el suyo sin tenerlas en cuenta; no hacerlo hubiera condenado su diccionario a parecer pobre o antiguo con respecto al de Domínguez. Debió de notar que el enriquecimiento en acepciones nuevas no siempre había sido realizado por el equipo de Domínguez según el mejor de los criterios, que este equipo a menudo había incluido algunas acepciones dadas por Bescherelle y dejado de lado otras según un criterio difícil de compartir; pero, aun así, consideraría que no le quedaba más remedio que reemprender la misma operación llevada a cabo por el equipo de Domínguez a partir del Bescherelle; quizá, eso sí, aprovechando una parte de lo que tal equipo ya había realizado, pero, en todo caso, intentando mejorar los resultados.

En resumen, tras la aparición del Domínguez, a Salvá solo le quedaba un camino: tenía que volver a empezar la composición de su diccionario francés-

29. Así lo suponemos en el caso de un diccionario bilingüe, dado que ni siquiera era partidario de multiplicar excesivamente los tecnicismos en los diccionarios monolingües. D. Azorín Fernández señala que el Nuevo diccionario de la lengua castellana (1846) de Salvá contiene un millar de voces técnicas y científicas más que la novena edición del Diccionario de la Real Academia, pero que, siendo una cifra nada despreciable, su actitud hacia estas voces fue la misma que la mantenida por la corporación en el prólogo de esa novena edición: la de poner coto a la tendencia de los lexicógrafos no académicos de la época a incorporar en masa tales vocablos a sus diccionarios (op. cit., 2003, p. 130). Lo que, en cambio, no es probable es que Salvá compartiera la condena que hace el prólogo del Nuevo diccionario de 1856 de la presencia de voces antiguas en el diccionario de Domínguez. Como ha puesto al descubierto P. Álvarez de Miranda, el monolingüe de Salvá recoge un alto número de ellas, entre las que cita un conjunto comprendido entre $b$ y bajoca que la Real Academia solo con posterioridad recogió en su diccionario (op. cit., 2002, p. 1881-1883). Hemos tenido la curiosidad de comprobar si alguna de las doce voces de ese conjunto se hallan como entrada en la parte español-francés del Nuevo diccionario de 1856: ninguna de ellas figura.

30. M. Seco («El nacimiento...», op. cit., p. 143) cita la condena lanzada por Salvá en la introducción de su diccionario monolingüe (op. cit., 1845, p. XIV) contra el sesgo subjetivista de ciertas definiciones (preadamita, selenita, incubo, súcubo) del diccionario de la Real Academia. 
español. No podemos saber a ciencia cierta si dudó un tiempo en hacerlo o si nunca lo hizo; pero lo seguro es que la aparición del Domínguez fue una razón de peso para dejar sin acabar un proyecto en el que siempre había estado empeñado. No se olvide que, aunque la publicación del Domínguez empezó en 1845, su último tomo vio la luz en 1846, muriendo Salvá en 1849: un lapso demasiado corto para que un hombre tan atareado y concienzudo como Salvá rehiciera su proyecto.

\subsection{Los estereotipos dejados por Salvá}

Acabamos de decir que desconocemos si Salvá comenzó o no, tras la aparición del Domínguez, la recomposición de la parte de su diccionario bilingüe que ya tenía lista para la imprenta. ¿Haría nuevos clichés a partir de los de 1840? ¿Reformaría éstos con los cambios que le parecieran necesarios tras la publicación del Domínguez?

No nos plantearíamos estas preguntas si no fuera por una declaración de su hijo, Pedro Salvá y Mallén. Como ya hemos indicado, éste publicó en 1872 un Catálogo de la rica biblioteca de libros antiguos que él y su padre habían allegado. También incluyó en él las obras de Vicente Salvá. El número 2280 de tal catálogo corresponde al Nuevo diccionario de 1856. Pedro Salvá lo comenta así:

Mi padre dejó abundantes materiales para la formación de este Diccionario; y la letra A y gran porcion de la B de la parte francesa-española, se han copiado al pie de la letra de lo que él tenía ya estereotipado á su fallecimiento. (P. Salvá y Mallén, op. cit., t. II, p. 271).

Pues bien, nuestro análisis de los artículos de la letra A del Nuevo diccionario nos ha descubierto que tanto la influencia del Bescherelle como la influencia del Domínguez son ya patentes en ellos; estas influencias son en la letra A tan claras como en el resto de la parte francés-español. Véase el artículo Aérolithe, que ha sido traducido al pie de la letra del Bescherelle por Domínguez y que ha pasado literalmente, salvo las reducciones y correcciones habituales, al Nuevo diccionario:

Domínguez. Aérolithe, s. m. a-é-ro-li-t. Aereolito, se da este nombre en mineralógia y en astronomía á unas masas minerales inflamadas, ya sólidas y duras, ya blandas y pulverulentas, que bajan de la atmósfera acompañadas constantemente de fenómenos luminosos y de detonacion. Al llegar cerca de la tierra estallan... [sigue una larguísima explicación enciclopédica]. Tambien se llaman globos de fuego, ó piedras caidas del cielo. [...] 
NUEVO DICCIONARIO. AÉROLITHE, m. aerolit. Aerólito: se da este nombre en mineralogía y astronomía á unas masas minerales inflamadas, que bajan de la atmósfera acompañadas constantemente de fenómenos luminosos y de detonacion. Tambien se llaman globos de fuego, ó piedras caidas del cielo.

La literalidad entre el Domínguez y el Nuevo diccionario es igualmente patente en otros muchos artículos de las letras A y B. Véanse affley affleurement, los cuales, al igual que aérolithe, no recoge Capmany, cuya influencia no puede, pues, invocarse en estos $\operatorname{casos}^{31}$ :

Domínguez. Affile, s. m. $a-f-l$. Art. Muñeca de lienzo llena de tocino ó grasa con que se untan algunos instrumentos cortantes para que corran mejor.

Domínguez. Affleurement, s. m. a-fleu-r-man. Nivelacion, reduccion de dos cuerpos contiguos á una misma superficie, sin que el uno sobresalga mas que el otro. || Min. Extremidad de una vena de ornaguera.

Nuevo diccionario. affile, m. afil. Art. Muñeca de lienzo llena de tocino ó grasa con que se untan algunos instrumentos cortantes para que corran mejor.

NUEVo DicCionario. afFleurement, $\mathrm{m}$. afleuremán. Nivelacion, reduccion de dos cuerpos contiguos á una misma superficie, sin que el uno sobresalga mas que el otro. \| Min. Extremidad de una vena de hornaguera.

Igualmente, como decíamos, la influencia del Becherelle en la letra A no se ejerce en el Nuevo diccionario sólo indirectamente a través del Domínguez, sino que, conforme a lo que ocurre en el resto de la obra, puede ser ya también directa. Obsérvese en el siguiente ejemplo cómo todo lo que en el Nuevo diccionario difiere de la definición que ofrece el Domínguez está inspirado del Bescherelle ${ }^{32}$ :

BesCHERELLE. ABAJOUE. [...] Les zoologistes donnent ce nom à une double poche qu'un assez grand nombre de mammiferes portent sur le côté de la bouche, soit à l'extérieur des joues, comme dans quelques rongeurs; soit à l'intérieur, entre les joues et les mâchoires, comme dans beaucoup de singes $[\ldots]$

- Dans le langage familier, on appelle abajoues des joues volumineuses et pendantcs. [...]

31. Nótese que, en la entrada affleurement, el Nuevo diccionario sustituye ornaguera por la forma académica hornaguera.

32. Recuérdese que el Bescherelle fue editado en 1845-1846. 
- Charcut. Parties latérales du groin de cochon et de la tête de veau lorsqu'ils sont cuits.

Domínguez. Abajoue, s. f. a-ba-jú. Bolsa que algunos mamíferos tienen en el espesor de los carrillos para conservar los alimentos antes de ser triturados.

Nuevo dicCionaRIo. abajoue, f. abajú. Bolsa que los monos y otros mamíferos tienen en el espesor de los carrillos. II La parte lateral del hocico cocido del puerco ó de la ternera. $\|$ fam. Papada.

De lo anterior parece desprenderse que, si Salvá y Mallén está en lo cierto en cuanto a que lo estereotipado para la letra A y parte de la B por su padre pasó al pie de la letra al Nuevo diccionario, y puesto que la influencia del Domínguez solo pudo ejercerse a partir de 1845, Salvá tuvo que haber cambiado sus estereotipos de 1840 en el transcurso de los últimos años de su vida. Hemos de considerar, no obstante, otra posibilidad: la de que el amor filial o un conocimiento superficial del Nuevo diccionario llevaran a Salvá y Mallén a una percepción equivocada de los hechos.

Poco tiempo después de la muerte de Salvá, sus herederos vendieron a los hermanos Garnier su librería parisina junto con los derechos de las obras que editaba. En el traspaso entraron los clichés de tales obras. Si los correspondientes al diccionario francés-español que Salvá había empezado a componer solo comprendían la letra A y una porción de la letra $\mathrm{B}$ de la parte francésespañol, Salvá y Mallén pudo pensar que Guim se sirvió de ellos sin más, sin introducirles reformas. En todo caso, hacia los años setenta, cuando redacta su Catálogo el hijo de Salvá, éste no tenía modo alguno de comprobar la conformidad de la impresión del diccionario realmente llevada a cabo con los estereotipos de su padre, que ya no le pertenecían. Por lo demás, e incluso si advirtió la introducción de algunos cambios, el hecho de que tanto la portada como el prólogo del Nuevo diccionario atribuyeran a Salvá una amplia participación en el nacimiento de la obra, pero sin explicar en qué consistía exactamente tal participación, pudo ser para Salvá y Mallén una invitación a reivindicar que su padre no se había limitado a legar unos materiales aptos para ser utilizados pero no organizados en forma de diccionario, como lo daba a entender la portada, sino que, además, había establecido el plan de la obra y había dado ejemplo de lo que debía ser su forma definitiva elaborando todos los artículos de una letra y los de parte de otra.

Nótese, por último, que los estereotipos de que habla Salvá y Mallén solo corresponden a la parte francés-español. Su comentario parece confirmar la declaración del propio Salvá en su carta 1841 (ver supra): que solo debía 
ocuparse, en principio, de esta parte de la obra, dejando la parte español-francés a Bourgoing o a algún otro. Esta dedicación preferente a la parte francésespañol no es de extrañar. Al igual que Capmany unos cincuenta años antes ${ }^{33}$, donde Salvá se sentiría realmente cómodo sería en esa parte francés-español ${ }^{34}$, la parte que le permitiría lucir un buen conocimiento de la lengua española, buscar sus matices, multiplicar los sinónimos o establecer incluso la forma culta mejor adaptada al español para traducir los abundantes neologismos del francés. ¿Tiene, entonces, visos serios de verosimilitud el que también la portada de la segunda parte, español-francés, del diccionario declare que está redactada «d'après les matériaux réunis par D. Vicente Salvá»?

\section{El PRESTIGIO DE UN NOMBRE}

Tras todo lo dicho, una nueva pregunta se nos plantea: ¿a quién debería considerarse como verdadero autor del Nuevo diccionario de 1856? ¿Es Salvá o lo son Guim y Noriega? Hasta aceptando la eventualidad de una aportación real por parte de Salvá en lo tocante al plan de la obra, creemos que sus verdaderos autores son Guim y Noriega. Sin negar la influencia de Salvá, pensamos que lo que este aportó sobre todo al diccionario fue el prestigio de su nombre.

\subsection{Hacia la asignación de autoría}

Después de la adquisición de la librería de Salvá por la casa Garnier, esta lanza al mercado, en 1852, nuevas ediciones de las tres obras que habían dado a Salvá más ganancias y renombre: su gramática española, su diccionario del español y su versión del bilingüe latín-español de Valbuena. Como hemos dicho, Garnier seguramente compraría, con los derechos de estas obras, los clichés preparados por Salvá para su futuro diccionario francés-español. Si Salvá consideraba -ya lo hemos visto- que este diccionario sería «de una gran utilidad" para la buena marcha de su editorial, los hermanos Garnier llegarían, sin duda, a la misma conclusión: tras comprobar los buenos resultados económicos que derivaban de la publicación de una gramática y un

33. Recuérdese que el diccionario de Capmany era unidireccional francés-español.

34. También cuando ayudó a Seoane en la edición de su diccionario se dedicó preferentemente a la parte inglés-español (véase nota 21 ). 
diccionario del español y de un diccionario latín-español ${ }^{35}$, pensarían, como Salvá, que faltaba a su serie sobre la lengua española un diccionario francésespañol y español-francés ${ }^{36}$. Sobre todo porque, si las otras tres obras estaban principalmente-aunque no sólo-destinadas a los hispanohablantes de España y América, el bilingüe que faltaba interesaría, además de a ese público, a un público francófono. Ahora bien, las tres obras a las que nos hemos referido se publicaban todas a nombre de Salvá, un nombre que incluso había acrecentado su fama tras la muerte del autor gracias a las nuevas reediciones de Garnier. La operación comercial perfecta para esta editorial solo podía, pues, resultar de la edición de un diccionario francés-español y español-francés a nombre del mismo autor: había que atribuírselo a Salvá y así lo hizo Garnier ${ }^{37}$. La

35. Las tres obras fueron reeditadas varias veces por los hermanos Garnier. El diccionario del castellano, por ejemplo, volvieron a reimprimirlo ya en 1854, dos años tan solo después de haberlo lanzado por vez primera. Sería entonces cuando los Garnier encargarían a Guim y Noriega la redacción del Nuevo diccionario, por lo menos si estos son exactos cuando dicen en el prólogo (pág. V) que tardaron ańo y medio en tenerlo a punto para la imprenta.

36. Garnier lanza también una colección de guías políglotas, entre las que está el Manuel de la conversation et du style épistolaire, à l'usage des voyageurs et de la jeunesse des écoles: Françaisespagnol, compuesto por F. Corona Bustamante y aparecido el mismo año (1856) del Nuevo diccionario.

37. La editorial Garnier no se decidió, en cambio, a reeditar la Gramática para los españoles que deseen aprender la lengua francesa que había publicado Salvá en 1847. La causa de ello pudiera ser que, en este campo, existian nombres aún más rentables. Es significativo que, para cubrir este hueco, la editorial jugara de modo parecido a cómo lo hizo con el Nuevo diccionario: buscó vender sus publicaciones apostando por la carta segura de explotar la fama de nombres ya consagrados. Le encomendó a A. Galbán la revisión de la gramática más conocida en la época, la de P.N. Chantreau (Arte de hablar bien francés, Madrid, Sancha, 1781), cuyo nombre se había convertido en sinónimo de gramática del francés para hispanohablantes. La versión de Galbán del Arte de hablar bien francés aparece así en 1863. Significativo también que, simultáneamente, Garnier hiciera lo mismo en lo referente a una gramática del español para los franceses. Si decir "un Chantreau» equivalía por entonces a decir "gramática del francés para los españoles", decir «un Sobrino" equivalía a decir "gramática del español para los franceses». En 1862, Garnier edita, pues, una Grammaire espagnole-française de Sobrino très complète et très détaillée, contenant toutes les notions nécessaires pour apprendre à parler et écrire correctement l'espagnol. Era igualmente Galbán quien se presentaba como revisor de esta venerable gramática, cuya primera edición data nada menos que de 1697. Ya a principios de siglo se había llevado a cabo una operación parecida con la misma obra; el editor P. Beaume, de Burdeos, encargó a F. Martínez la publicación de una gramática que se apropiaba del nombre de F. Sobrino en su título: Nouveau Sobrino ou Grammaire Espagnole-Française, simplifiée et réduite à XIII leçons (1809). Las apropiaciones de la gramática de Chantreau son tan numerosas que no hay aquí espacio para consignarlas; sobre ellas puede consultarse M. A. Tost Planet, "Les avatars d'un grammairien, maître de langues et révolutionnaire: Pierre-Nicolas Chantreau", Documents pour l'histoire du français langue étrangère ou seconde, 13, 1994, p. 50-52. 
casa editora no se atrevió a inventar, en un principio, que lo había redactado Salvá, pero sí provocó que el público acabara considerándolo como el autor de la obra. Conseguido esto, Garnier se lo atribuyó abiertamente a Salvá. La operación la llevó a cabo, no obstante, con cierta prudencia.

En la primera edición de 1856, Garnier $^{38}$ ya imprimió más cerca del título el nombre de Salvá que el del redactor de cada parte, Guim o Noriega respectivamente. Si bien es verdad que en esta primera edición el nombre de Guim aparece en la portada francés-espańol con caractcres dc mayor tamańo que el de Salvá, curiosamente, en la portada interior, la de la parte espańol-francés (es decir, precisamente en la parte que menos le había interesado a Salvá, como ya hemos explicado), el nombre de Salvá, con su lugar preeminente tras el título, dobla asimismo en tamańo al de Noriega: era un primer paso para que el diccionario acabara siendo conocido como el de Salvá.

El paso siguiente lo dio la editorial solo dos años después, en la segunda edición (1858). Como en la primera, en ambas portadas sigue apareciendo más cerca del título el nombre de Salvá, pero esta vez, además, los nombres de Guim y Noriega aparecen, en sus respectivas portadas, en letras de tamaño casi tres veces más pequeño que las que conforman el nombre de Salvá, lo que hace que casi pasen desapercibidos en medio de las diversas explicaciones de que están rodeados. Y, para resaltar mejor el nombre de Salvá, este apellido, como ya era el caso en la primera edición, está precedido en ambas portadas de su nombre de pila al completo (Vicente Salvá), mientras que solo las iniciales de los nombres de pila de Guim y de Noriega acompańan a sus apellidos (J. B. Guim y F. de P. Noriega). Más aún, la disposición de la portada principal ${ }^{39}$ lleva a que el nombre de Salvá vaya precedido -en su mismo renglón, además- de un por en grandes caracteres, es decir, de un por que

38.Tanto la fecha de la primera edición del Nuevo diccionario como la editorial que la lanzó han figurado de modo diverso en distintos trabajos. Algunos estudiosos se han dejado confundir por el error que cometió G. Suárez Gómez al dar como edición princeps Besançon, 1836 («Avec quels livres les Espagnols apprenaient le français (1520-1850)», Revue de littérature comparée, 35, 1, 1961, p. 343). Pero él mismo señala a continuación que la primera edición que ha podido localizar es la que corresponde al ejemplar 1/34987 de la Biblioteca Nacional de España, publicado por Garnier, en París, en 1856. Con este mismo ejemplar hemos trabajado nosotros y hemos podido comprobar que ciudad, editorial y año son los indicados para él por Suárez Gómez. Además de Suárez Gómez, también otros estudiosos señalan Besançon para la primera edición, pese a asignarles, contrariamente a él, la fecha correcta de 1856. Esto proviene de que en el Catálogo de Salvá y Mallén (op. cit., tomo II, p. 271) se dan para nuestra obra estos datos: «Besanzon, Viuda Deis, 1856».

39. Hablamos de portada principal por ser la primera, la portada en espańol de la primera parte de la obra. La portada en francés de la segunda parte se halla hacia la mitad del volumen. 
pudiera hacer creer al lector poco atento que Salvá era el verdadero autor. La preposición se justificaba por la frase, en pequeños caracteres, situada entre el título y el nombre de Salvá. Véase, en el anexo situado al final de este artículo, una transcripción, guardando las proporciones originales, de la portada de la segunda edición de 1858 .

\subsection{Posteriores vicisitudes de un nombre}

El diccionario francés-español y español-francés editado por la casa Garnier fue un éxito comercial. Mucho tiempo después de la última reedición de las tres obras más famosas de Salvá -su gramática, su diccionario del español y su versión del Valbuena-, el Nuevo diccionario seguía estando disponible en el mercado. De tal modo sobrevivió a ellas, que sus reediciones, revisadas por diferentes lexicógrafos pero siempre lanzadas por la editorial Garnier, alcanzan el último cuarto del siglo XX. Como acabamos de explicar, el nombre de Salvá desempeñó, a nuestro modo de ver, un papel importante en este éxito. Es más, en la larga historia del diccionario, el nombre de Salvá llegó incluso a ganar mayor protagonismo.

Las reediciones de la obra en gran formato siguieron saliendo con las mismas portadas que la segunda edición: aunque en caracteres más pequeños, los nombres de Guim y Noriega siguen constando en ellas. Por el contrario, en las portadas de las ediciones de bolsillo, inmediatamente surgidas de la versión gran formato, no se lee más que el nombre de Salvá; los nombres de Guim y Noriega ya no aparecen en ellas.

Al principio, el nombre de Salvá siempre aparece en estas ediciones de bolsillo precedido por una indicación similar a la que figura en la versión gran formato. En la portada de la séptima edición de bolsillo (1868), por ejemplo, se lee todavía: "Compuesto con presencia de los materiales reunidos por D. VICENTE SALVÁ y con arreglo á los mejores diccionarios publicados hasta el dia.» En la decimoquinta (1881) o en la vigesimoquinta (1897) esta indicación no ha cambiado. Pero la edición que incorpora un suplemento de M. de la Torre ( $c a$. 1899) presenta una innovación. En su portada ya no hay ninguna referencia a los materiales reunidos por Salvá; este es presentado abiertamente como autor del diccionario: «Nuevo diccionario / francés-español / con la pronunciación figurada / por / D. Vicente Salvá». Fs más, simultáneamente a esta edición de bolsillo, pero en formato diferente, Garnier saca una reedición del diccionario revisada por Belmonte; Salvá figura igualmente en su portada como autor de la obra y su nombre va impreso en caracteres de mayor tamańo que los usados para el nombre del revisor Belmonte: «Nuevo 
/ diccionario / francés-español y español-francés / el más completo de los publicados / con la pronunciación figurada por los medios más / racionales y fáciles / por / Don Vicente SALVÁ / [...] Edición cuidadosamente revisada [...] / por / H. de Belmonte.»

Pero el proceso no ha terminado. A principios del siglo XX, a Salvá se le presenta ya como el verdadero autor de la obra, tal como acabamos de ver. El término Salvá impreso en portada todavía correspondía por entonces a un nombre de persona; iba preccdido dcl nombre de pila y del Don de un individuo real. A lo largo del siglo XX, sin embargo, el vocablo Salvá se irá convirtiendo en un nombre genérico, en el nombre de una colección en cierto modo. Así, en la edición de 1951, revisada por Larrieu y García Morente, son los nombres de éstos los que ocupan la parte central de la portada, mientras que el de Salvá, aunque en grandes caracteres, figura arriba del todo, delante del título, aislado, sin nombre de pila: «Salvá / Diccionario moderno / español-francés / y / francés-español / Nueva edición enteramente refundida y aumentada / por / Robert Larrieu [...] / y / Manuel García Morente [...]» Ciertamente, el prólogo recuperaba el nombre completo del autor:

Este diccionario que ofrecemos al público de habla española y francesa, es una edición modernizada y puesta al día de la obra clásica de Don Vicente Salvá que durante tantos años ha constituido la base indispensable para el aprendizaje del francés por los españoles como del espańol por los franceses. (1951, prólogo, p. XIII).

Pero este mismo prólogo muestra bien, asimismo, que si el nombre de Salvá seguía figurando en la portada era porque se había convertido, tras varias generaciones de usuarios hispanohablantes y francófonos, en una especie de nombre genérico para los diccionarios francés-español y, por consiguiente, en un nombre aún rentable para la editorial Garnier. Decir Salvá era decir «diccionario francés-español»; pedir un Salvá y comprarlo era comprar un producto de la casa editora Garnier, incluso si esta última parte podía pasar desapercibida para el comprador ${ }^{40}$.

40. Señalemos de paso que Garnier aprovechó el nombre de Salvá incluso fuera del ámbito francoespañol. A principios del siglo XX publica un Nuovo dizionario Italiano-Spagnuolo e Spagnuolo-Italiano: Contenente tutti $i$ vocaboli della lingua pratica colla pronunzia figurata delle parole italiane nei casi difficili compilato sopra i migliori testi contemporanei spagnuoli ed italiani, il piu completo di tutti i dizionari finora pubblicati : Arricchito di uno specchio dei verbi ausiliari, regolar / per cura di Salvá e Arturo Angeli Enenkel. Pocos años después, el juego de imitaciones propias de la edición de diccionarios hace que el nombre de Salvá aparezca en una obra editada en Italia: la editorial Casanova de Turín publica en 1924 
En 1981, la casa Diáfora de Barcelona reedita la versión de Larrieu y García Morente según el copyright de 1951. Pero, como la editorial quiere dar impresión de modernidad, cambia la cubierta, el formato, la distribución de los preliminares: nada que ver, aparentemente, con los diccionarios del pasado. El título del diccionario también cambia; se adapta a las consignas de las nuevas técnicas de venta: Diccionario maior francés-español españolfrancés Diáfora. El término Salvá no podía ser bien acogido en una edición de este tipo; recordaba demasiado la tradición. Los nombres de Larrieu y García Morente, en cambio, no connotaban nada para el gran público. De ahí que Salvá no aparezca por ningún sitio en la portada de 1981; en ella, inmediatamente después del título, lo que se lee es: «Por Robert Larrieu [...] Manuel García Llorente ${ }^{41}$ ». Mientras que el nombre de Salvá favoreció las ventas, su nombre figuró en la portada del diccionario; en cuanto que dejó de hacerlo, D. Vicente Salvá fue desposeído del derecho de autoría que graciosamente se le había otorgado en exclusividad a principios del siglo XX. Por lo menos en lo que a la portada se refiere; el prefacio de 1981, simple reimpresión del de 1951, confiesa aún, imprudentemente, que el diccionario deriva «de l'ouvrage classique de Vicente Salvá». Pero ¿acaso leen los prólogos los usuarios de diccionarios? Y si los leen, ¿lo hacen antes de comprarlos?

\section{Para acabar}

Hasta aquí una parte de la historia del diccionario francés-español y español-francés de Salvá. En nuestra opinión, la obra debiera conocerse como diccionario de Guim y Noriega. Mas hoy día, y desde antiguo, para encontrarlo en los catálogos de las librerías, en los ficheros de las bibliotecas o en las bibliografías de los estudios lexicográficos, hay que buscarlo casi

un Nuovo vocabolario moderno razionale pratico italiano-spagnuolo, spagnuolo-italiano: contenente tutti $i$ vocaboli della lingua pratica colla pronunziafigurata ecc... / per cura di Salva e Angeli Enenkel.

41. En la portada aparece, en efecto, Llorente en vez de Morente. Este profesor de la Universidad de Madrid murió en 1942, lo que por sí mismo puede dar una idea de la modernidad del diccionario de Diáfora. Ya señalaba R. A. Verdonk que su «nomenclature est identique à celle de Salvá/Larrieu/García Morente 1951» («La lexicographie bilingue espagnol-français, français-espagnol", Wörterbücher, Dictionaries, Dictionnaires: Ein internationales Handbuch zur Lexicographie / An International Encyclopedia of Lexicography / Encyclopédie internationale de lexicographie, ed. por F. J. Hausmann, O. Reichmann, H. E. Wiegand y L. Zgusta, Berlín I Nueva York, Walter de Gruyter, t. 3, 1991, p. 2980). 
siempre a nombre de Salvá ${ }^{\prime 2}$. El propio hijo de don Vicente, sin embargo, no se atrevió a llegar tan lejos como lo hacemos hoy día influenciados por las maniobras comerciales que hemos explicado. Ya hemos dicho que en 1872, en su Catálogo, Salvá y Mallén quiso resaltar la participación de Vicente Salvá en la composición del Nuevo diccionario de 1856 . Aunque las obras consignadas en el catálogo pertenecen en su mayoría a la categoría de libros raros, bajo la entrada Salvá recoge, a modo de homenaje, las obras compuestas por su padre con todas sus reediciones $\left(\mathrm{n}^{\circ} 2402\right.$ a 2422). Pues bien, el Nuevo diccionario no figura entre ellas: las entradas del catálogo siguen el orden alfabético de los nombres de autor, pero el Nuevo diccionario no está entre las entradas de la letra S de Salvá, sino entre las entradas de la letra G de Guim ( ${ }^{\circ} 2280$ ).

42. Hágase una prueba buscando, por ejemplo, en el Catalogue BN-OPALE PLUS de la Bibliothèque nationale de France las obras de Guim. Se verá que el Nuevo diccionario de 1856 se le atribuye a éste solamente como "éditeur scientifique», asignándose la autoría de la obra a V. Salvá. En ciertos casos, los catálogos caen incluso en contradicciones flagrantes. Así, en el volumen 6 (Les manuels d'espagnol, 1995) de la serie Les manuels scolaires en France de 1789 à nos jours (dir. por A. Choppin, París, INRP, Publications de la Sorbonne), hay dos entradas diferentes para el Nuevo diccionario de 1856: una $\left(n^{\circ} 166\right)$ solo da el título en francés de la segunda parte español-francés, presentando a Noriega como autor de la obra y a Salvá como lexicógrafo meramente citado en la portada; la otra, inmediatamente después de la anterior $\left(n^{\circ} 167\right)$, da el título en español correspondiente a la primera parte, presenta a Salvá como autor de la obra y no hace mención alguna de Guim. 


\section{ANEXO}

\section{NUEVO DICCIONARIO \\ FRANCES-ESPAÑOL Y ESPAÑOL-FRANCES,}

\section{CON LA PRONUNCIACION FIGURADA EN AMBAS LENGUAS,} ARREGIADO) CON PRESENCLA DE LOS MATERIALES RLEUNIDOS PARA ESTA ORRA

\section{POR D. VICENTE SALVÁ,}

Y CON OTROS SACADOS DE LOS DICCIONARHS ANTIGUOS Y MODERNOS MAS ACREDTTADOS:

COMMUESTO CON MEJOR MITODO, MAS EXACTO. CORRECTO Y COMPLETO QUE TOOOS LOS PUBBICARXS HASTA EL DIA.

\section{POR D. J. B. GUIM,}

